\title{
Impacto prospectivo da tecnologia do xaxim agroecológico utilizando o Inova-Tec System v 2.0
}

\author{
Prospective Impact of technology Xaxim Agroecological using the Inova-Tec System v 2.0
}

\author{
Ana Cristina Siewert Garofolo ${ }^{{ }^{*}}$ Cristhiane Oliveira da Graça Amancio ${ }^{\mathrm{I}}$
}

RESUMO

O Xaxim, vaso ou suporte utilizado para o cultivo de diversas espécies de plantas ornamentais, tinha sua produção realizada a partir do caule de plantas de Dicksonia sellowiana. Atualmente esta espécie está ameaçada de extinção sendo sua extração proibida por lei federal. Como solução, a Embrapa Agrobiologia desenvolveu o Xaxim Agroecológico, tecnologia inovadora, que utiliza o enraizamento do milheto (Pennisetum glaucum) para agregar o substrato e formar a estrutura do vaso. Com o intuito de uma gestão adequada da inovação procurou-se realizar estudo do impacto tecnológico pautado em parâmentros econômicos e mercadológicos mensurados via análises prospectivas. Nesta situação a avaliação ex-ante representa um componente essencial para elaboração de cenários prospectivos e fator orientador para a empresa geradora da inovação. Nesta pesquisa procurou-se realizar uma avaliação ex-ante da tecnologia do Xaxim Agroecológico dentro do proposto metodologicamente pelo INOVA-tec System v 2.0., pautada em indicadores pertinentes a invenção. Resultados encontrados apontam para a confiabilidade do uso do programa em avaliações prospectivas de tecnologia agroecológica, desde que sejam considerados indicadores adicionais, conforme a situação a ser analisada. $O$ uso do INOVA-tec System v 2.0 para o Xaxim Agroecológico, demonstrou potencial tecnológico com cenário propicio para a inovação, desde que ocorram melhorias nos indicadores que compõe as dimensões ambiental e econômica.

Palavras-chave: avaliação ex-ante, prospecção, Inova-tec System $\checkmark 2.0$.

\section{ABSTRACT}

The Xaxim, vase or medium used for the cultivation of various species of ornamental plants, their production was made from the stems of plants of Dicksonia sellowiana. Currently this species is endangered and its extraction prohibited by federal law. As a solution, Embrapa Agrobiology developed Xaxim Agroecological, innovative technology that utilizes the roots of pearl millet (Pennisetum glaucum) to add the substrate and form the structure of the vase. In order to proper management of innovation attempted to make the study of technological impact parameter settings guided by economic and market measured via prospective analyzes. In this situation the ex-ante evaluation is an essential component for developing future scenarios and guiding factor for the company generating innovation. In this research we tried to carry out an ex-ante evaluation of Xaxim Agroecological within the methodology proposed by INOVA-tec System v 2.0. based on indicators relevant to the invention. For Xaxim Agroecológico, using INOVA-tec System v 2.0, demonstrated with a potential scenario conducive to technological innovation from occurring improvements in indicators that make up the environmental and economic.

Key words: ex-ante evaluation, Prospecting, Inova-tec System $v$ 2.0 .

\section{INTRODUÇÃO}

O xaxim é um vaso ou suporte utilizado para o cultivo de diversas espécies de plantas ornamentais. É um produto de grande aceitação popular, com utilização em todo o território nacional. Sua produção era realizada a partir do caule de plantas de Dicksonia sellowiana, espécie também conhecida como xaxim. A extração desta espécie, porém, foi proibida por Lei Federal (BRASIL, 2001), pois essa espécie, que é oriunda da Mata Atlântica, em especial nos estados das regiões sul e sudeste, está ameaçada de extinção. Assim sendo, não é mais possível ofertar vasos de xaxim no mercado, fato, esse, que gerou a necessidade de busca por produtos alternativos.

\footnotetext{
IEmbrapa, Centro Nacional de Pesquisas em Agrobiologia, Rodovia BR 465, Km 47, 23891-000, Seropédica, RJ, Brasil. E-mail: ana.garofolo@embrapa.br.*Autor para correspondência.
} 
Considerando a importância em se ter tecnologias ambientalmente adequadas, a Embrapa Agrobiologia desenvolveu um método inovador que permite confeccionar vasos muito parecidos com os que eram obtidos anteriormente com o caule de Dicksonia sellowiana. O Xaxim Agroecológico da Embrapa (patente número PI0903244-4 A2, depósito em 07/08/2009) emprega um processo de produção inovador, que utiliza o enraizamento vegetal para agregar o substrato e formar a estrutura do vaso. O milheto, espécie Pennisetum glaucum, é uma planta muito rústica e não exige cuidados especiais, possuindo rápido crescimento e quando cultivado em substrato com elevado teor de matéria orgânica, proporciona a formação de um emaranhado com grande volume de raízes, produzindo estruturas com características muito parecidas com as do xaxim original (LEAL, 2009). Assim sendo, a tecnologia do Xaxim ecológico emprega matéria-prima abundante e renovável e os vasos são produzidos sem utilização de cola ou resina, visto seu vedamento ser feito com cera de carnaúba. O xaxim agroecológico é totalmente biodegradável e, após a sua deterioração, transforma-se em húmus. Os xaxins descartados podem ser fragmentados e utilizados como substrato para preencher outros vasos, ou serem depositados em canteiros de plantas. Trata-se de uma tecnologia adequada ambientalmente perante as leis ambientais vigentes no país, e passível de transferência para terceiros que se predisponham a produzi-lo para o mercado ou uso em propriedades rurais. Dessa forma estudos prospectivos tornam-se necessários para um efetivo processo de transferência tecnológica.

Um processo de transferência de tecnologia pressupõe um percurso desde o início da pesquisa até seu trâmite no mercado com suas respectivas repercussões (ROCHA et al.,2010). Assim sendo o sucesso de uma tecnologia depende, além de sua viabilidade técnica, de parâmetros econômicos e mercadológicos os quais poderão ser mensurados via analises ex-ante e ex-post.

A avaliação geral do impacto de uma tecnologia deve consequentemente pautar-se em avaliações prospectivas e avaliações posteriores a implantação desta junto ao púbico receptor (RODRIGUES, 1998, RODRIGUES et al., 2002, RODRIGUES et al., 2003a). Geralmente a avaliação ex-ante permite a construção de um cenário prospectivo para todos os atores envolvidos na concepção da inovação tecnológica, sendo voltada para diagnosticar impactos potenciais de interesse para agentes financiadores e fomentadores (JESUSHITZSCHKY, 2007).
Salienta-se que o fato de a tecnologia já ter sido desenvolvida, não afeta a realização da avaliação ex-ante, sendo que ocorre nessa situação, é que algumas das informações usadas na avaliação já estarão disponíveis, não sendo necessário projetálas. Enquanto houver a necessidade de projeção de resultados futuros, como no caso da tecnologia em questão, a avaliação ex ante se fará pertinente. Logo a avaliação prospectiva dos impactos das tecnologias atua como uma aliada do processo de tomadas de decisões, necessárias para o processo de transferência da tecnologia, que apesar do patenteamento em 2009, apenas em 2012 teve seu processo iniciado pela Embrapa Agrobiologia.

Avaliações ex-post, que não são objeto de estudo neste artigo, avaliam o desempenho da tecnologia no mercado sendo interessante aos órgãos fiscalizadores e regulamentadores, empresas compradoras de tecnologia e para a sociedade de maneira geral.(JESUS, 2011).

O objetivo do presente trabalho foi realizar a avaliação prospectiva da tecnologia do Xaxim Agroecológico utilizando o Software Inovatec System v 2.0 a partir de adaptações que sejam necessárias.

\section{MATERIAL E MÉTODOS}

O INOVA-tec (JESUS, 2011) apresentase como um software para avaliações de impactos de Inovações Tecnológicas, organizadas segundo indicadores e critérios específicos. O sistema proposto foi pautado em métodos usados para análise de risco de Plantas Geneticamente Modificadas - GMP-RAM - Risk Assessment Method for Genetically Modified Plants (JESUS-HITZSCHKY et al., 2006) e de avaliação de impacto ambiental utilizado por ocasião de implantação do Sistema ISO 14.000. Trata-se de um software de livre acesso que possibilita ao avaliador indicar os parâmetros específicos para a avaliação mais criteriosa da sua inovação possibilitando a análise caso-a-caso e com isto o emprego da inovação de maneira responsável e criteriosa.

Impactos poderão ser mensurados de maneira direta ou indireta nas dimensões social, ambiental, econômica, desenvolvimento institucional e capacitação, introdução da tecnologia e ocorrências inesperadas através de indicadores organizados em critérios para cada uma das dimensões avaliadas. Desse modo, espera-se que uso dos indicadores no sistema INOVA-tec diminua a subjetividade da avaliação possibilitando uma analise mais responsável e criteriosa da inovação. 
O sistema permite avaliar a abrangência da inovação e o seu desempenho através de um Índice de Impacto Geral gerado através de dois índices que se complementam: significância (análise prospectiva) e magnitude (desempenho dos indicadores) (JESUSHITZSCHKY, 2007).

A construção do quadro de indicadores a serem utilizados como parâmetros devem ser consolidados a partir de um painel de oito especialistas, composto de pesquisadores e analistas da área de Transferência de Tecnologias da Embrapa Agrobiologia além do pesquisador autor do Xaxim Agroecológico em estudo.

A avaliação prospectiva da tecnologia segundo o INOVAtec considera a extensão da sua aplicação, alcance da tecnologia e sua influência quando a análise desss fatores de moderação permite a geração do Índice de Significância (JESUS, 2011). Esse índice é calculado pela multiplicação da extensão pela abrangência da inovação, sendo esta uma somatória do alcance de cada dimensão pela sua influência.Os fatores de moderação para cálculo do Índice de Significância propostos pelo método estão descritos em Jesus (2011).

A determinação do índice de magnitude é feito através da organização dos indicadores de acordo com o foco das dimensões social, ambiental, econômica, desenvolvimento institucional, capacitação, introdução da tecnologia, ocorrências inesperadas e outros específicos que possam ser considerados relevantes à pesquisa, visto ser o software personalizável (JESUS, 2011). Da mesma forma o avaliador pode analisar apenas os indicadores considerados relevantes, sem distorção do resultado final (Jesus, 2011). O software apresenta dezessete critérios e cinquenta e três indicadores distribuídos nas sete dimensões. Para a avaliação ex-ante Jesus (2011) sugere os critérios e indicadores apresentados na tabela 1.

Aos critérios apresentados na tabela 1 como necessários para a avaliação prospectiva considerouse também para avaliação ex-ante da tecnologia do Xaxim Agroecológico, o critério divulgação cientifica para a dimensão social, pautado em ações de divulgação prévia e lançamento da tecnologia. Neste critério foram considerados os indicadores matéria jornalística/mídia e número de palestras/cursos ministrados frente ao público presente e número de participantes. Para a dimensão econômica foram considerados também os indicadores domínio da cadeia produtiva e barreiras de entrada no mercado.

Após o cálculo dos índices de significância e magnitude determinou-se o índice de impacto potencial e do cenário prospectivo para a introdução da tecnologia conforme o descrito em Jesus (2011).

\section{RESULTADOS E DISCUSSÃO}

Com o objetivo de traçar o cenário da inovação tecnológica inicialmente procedeu-se à análise da significância considerando extensão da sua aplicação, alcance da tecnologia e sua influência, através de valores atribuídos por um painel de especialistas. A pesquisa foi realizada no formato de uma entrevista presencial para identificação e atribuição do peso dos indicadores necessários, faixas de peso de cada fator de moderação e dos fatores de correção, se necessários, incluindo-se a extensão de sua utilização em pontual, local, regional, nacional e internacional. Os dados ponderados são apresentados na tabela 2 quando são apresentados todos os valores que geraram o índice de significância por alcance e influência.

Os indicadores que apresentam um peso maior são aqueles com impacto potencializado. Para a tecnologia do Xaxim Agroecológico considerou-se a dimensão ambiental com peso 3, uma vez que a não extração do xaxim de Dicksonia sellowiana em seu ambiente natural possibilita a recuperação da espécie em seu ambiente contribuindo para conservação ou preservação. Da mesma maneira, é atribuído o valor máximo (3) para a dimensão econômica visto que pesquisas prévias realizadas pelo autor da invenção demonstraram potenciais reais para comercialização da invenção. Da mesma forma indicadores com menor número representam aqueles com menor impacto.

O valor final do desempenho de cada dimensão será o resultado da somatória dos valores de todos os indicadores, dentro da dimensão avaliada, as quais por determinação metodológica serão consideradas igualmente importantes. Isto permitirá a elaboração de uma lista de recomendação com a finalidade de potencializar o impacto positivo da inovação para cada dimensão (JESUS, 2011). A figura 1 a seguir apresenta o desempenho das dimensões consideradas nesta avaliação.

Para a tecnologia do Xaxim Agroecológico os indicadores pontuados na dimensão ambiental foram: alteração de demanda por recursos naturais, prática de manejo ou monitoramento ambiental, diminuição do nível de poluentes sólidos, químicos e biológicos, e a possibilidade de recuperação de um ecossistema ameaçado. Estes últimos destacaramse graças ao fato de que o Xaxim Agroecológico ao evitar a extração do xaxim natural permite a preservação de ecossistemas e consequentemente mananciais naturais. 
Tabela 1 - Critérios e Indicadores usados para avaliação Ex-ante.

\begin{tabular}{|c|c|c|}
\hline Dimensão & Critério & Indicador \\
\hline \multirow[t]{4}{*}{ Ambiental } & Conservação ambiental & Pratica de manejo ou monitoramento ambiental \\
\hline & & $\begin{array}{l}\text { Diminuição do nível de poluentes sólidos, } \\
\text { químicos, biológicos }\end{array}$ \\
\hline & Recuperação ambiental & Mecanismos de biodegradação \\
\hline & & $\begin{array}{l}\text { Atua na estabilidade de um ecossistema } \\
\text { ameaçado }\end{array}$ \\
\hline \multirow{2}{*}{ Capacitação } & \multirow{2}{*}{ Formação de Recursos Humanos } & Número de estagiários \\
\hline & & Número de pós-graduandos \\
\hline \multirow[t]{9}{*}{ Desenvolvimento Institucional } & Aporte de recursos & Formas de aporte de recursos \\
\hline & Formalização de parcerias & Convenio formado \\
\hline & Parceiras & Numero de parceiros \\
\hline & \multirow{2}{*}{ Sistema de qualidade implantado } & Atendimento normativo \\
\hline & & Selo ISO ou outro selo de qualidade \\
\hline & \multirow{8}{*}{ Econômico } & Retorno Qualitativo \\
\hline & & Aumento de Divisas \\
\hline & & Pagamentos/recebimentos de Royalties \\
\hline & & Mercado no qual a inovação será inserida \\
\hline \multirow[t]{4}{*}{ Econômico } & & Perspectiva de mercado (tamanho da demanda) \\
\hline & & $\begin{array}{l}\text { Ciclo de vida do produto (reflete o tempo que o } \\
\text { produto permanecerá no mercado) }\end{array}$ \\
\hline & & Valor agregado \\
\hline & & A inovação é passível de comercialização \\
\hline \multirow[t]{5}{*}{ Introdução da inovação } & Avanço tecnológico & Tipo de Inovação \\
\hline & \multirow{4}{*}{ Desdobramento comercial } & Registro de patente \\
\hline & & Registro de variedade ou cultivar \\
\hline & & Registro de software \\
\hline & & Transferência de Tecnologia \\
\hline Social & Alcance social & Classe social beneficiada pela inovação \\
\hline
\end{tabular}

Fonte: Adaptado de Jesus (2011).

Para a dimensão econômica entre os indicadores pontuados na metodologia proposta por Jesus (2011) como representativos destacaram-se a possibilidade de comercialização e pagamentos e recebimentos de royalties o qual se apresentou como pertinente visto o patenteamento conseguido pela tecnologia junto ao Instituto Nacional de Propriedade Intelectual. Assim sendo, o Xaxim Agroecológico apresenta potencial inserção na cadeia produtiva de flores e ornamentais, visto que pode substituir ou complementar um elo importante que é o de recipientes.
Segundo GEHLEN (2004) uma estratégia para minimizar a exclusão social, no meio rural, é a incorporação de recursos tecnológicos de baixo custo, sendo que diversas experiências de tecnologias sociais desenvolvidas e difundidas com este objetivo têm possibilitado o reforço em favor de uma agricultura sustentável, em que o direito à vida e as condições dignas às pessoas do campo ficam fortalecidos. Logo ganhos socioeconômicos podem ser representados pela possibilidade de geração de renda para novos 
Tabela 2 - Peso e Influência dos indicadores utilizados.

\begin{tabular}{lclc}
\hline Alcance da Inovação & Peso & Influência & Total \\
\hline Econômico & 3 & Direta & 6 \\
Legal & 1 & Direta & 2 \\
Meio Ambiente & 3 & Direta & 6 \\
Político & 1 & Nula & 0 \\
Qualid.Pesq.Prod & 2 & Direta & 4 \\
Saúde Humana & 1 & Indireta & 1 \\
Social & 2 & Direta & 4 \\
\hline
\end{tabular}

Fonte: Elaborado pelos autores do artigo (2012).

empreendedores, bem como abertura de novos mercados para o setor de floricultura e ornamentais.

Para a dimensão social vários indicadores foram pontuados dentro dos previstos pelo programa (JESUS, 2011), entre os que abrangem desde a disseminação do conhecimento (matéria jornalística / mídia e número de palestras ou cursos ministrados, número de participantes e tipo de público) até a geração de novos postos de trabalho e a valorização de classes sociais que possam ser beneficiadas pela inovação. Para o caso específico do Xaxim Agroecológico observa-se que a possibilidade de geração de postos de trabalho direto e indireto contribui para que ele venha a constituir-se como possuidor de grande impacto socioeconômico. Seja como for, toda e qualquer estratégia de inserção de novas tecnologias sociais sustentáveis somente terá sucesso quando amparada em políticas públicas de apoio financeiro e técnico, de qualificação profissional e de infraestrutura (GEHLEN, 2004).
A partir dos valores apresentados calculouse a abrangência e o índice de significância conforme descrito por Jesus (2011), os quais resultaram nos valores 23 e 92 respectivamente. O índice de magnitude, calculado a partir da análise os indicadores para as diferentes dimensões gerou um valor de 9,428. Esse índice caracteriza os indicadores com baixo desempenho para as dimensões consideradas na analise da tecnologia.

O resultado da avaliação da tecnologia do Xaxim Agroecológico e a recomendação do gerenciamento necessário do impacto com vistas a mitigar efeitos negativos são apresentados na Matriz de Impacto apresentado na figura 2 a seguir.

Considerando os valores de significância e magnitude calculados, encontramos um cenário propício para a inovação, porém com baixo desempenho dos indicadores considerados estratégicos para a inovação em questão. A partir da análise dos resultados cruzados na matriz de impacto apresentada na figura 2 ações de valoração de outros indicadores de análise de impacto da inovação tecnológica deverão devem ser recomendadas. Assim sendo os impactos potenciais se pautarão em possibilidades de melhorias dos aspectos econômicos, sociais e ambientais proporcionado pelo lançamento da tecnologia do Xaxim Agroecológico. É proposta pelas autoras deste artigo uma nova avaliação prospectiva quando do lançamento da tecnologia no mercado sendo pertinente considerar na dimensão ambiental os impactos nos recursos hídricos solo e ar entre os quais alterações na qualidade da água em decorrência da introdução da inovação e alteração

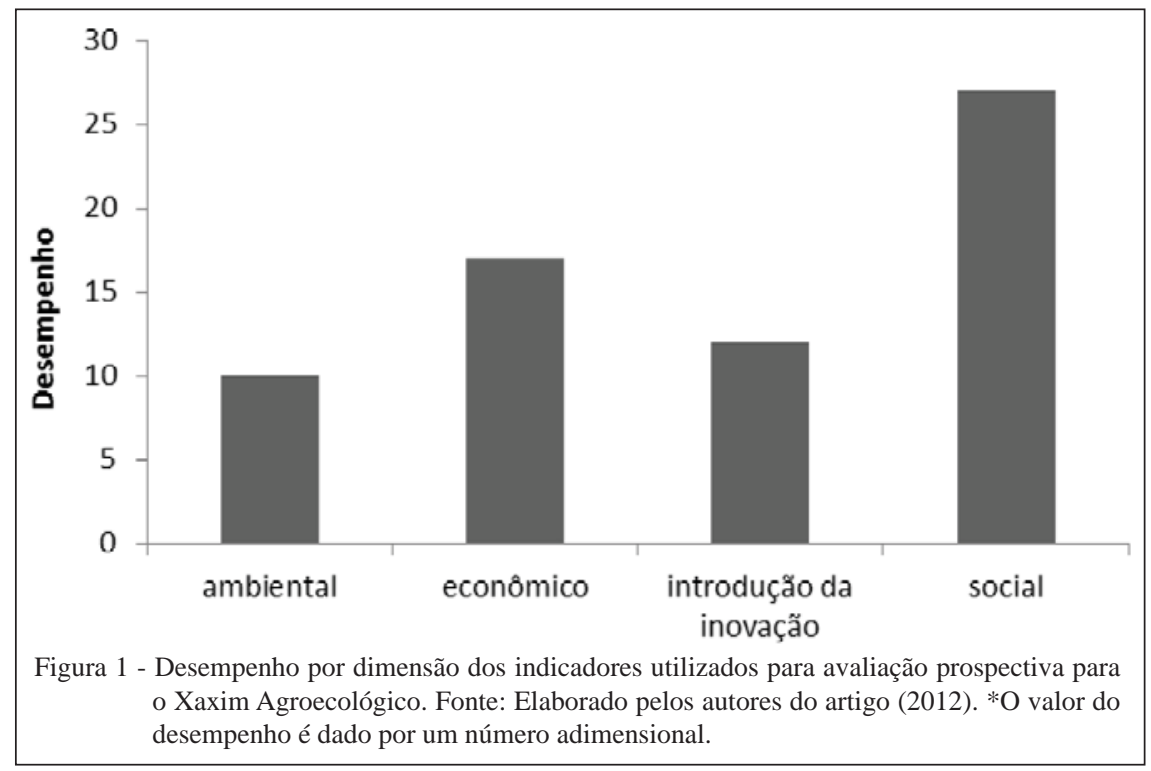

Ciência Rural, v.43, n.11, nov, 2013. 


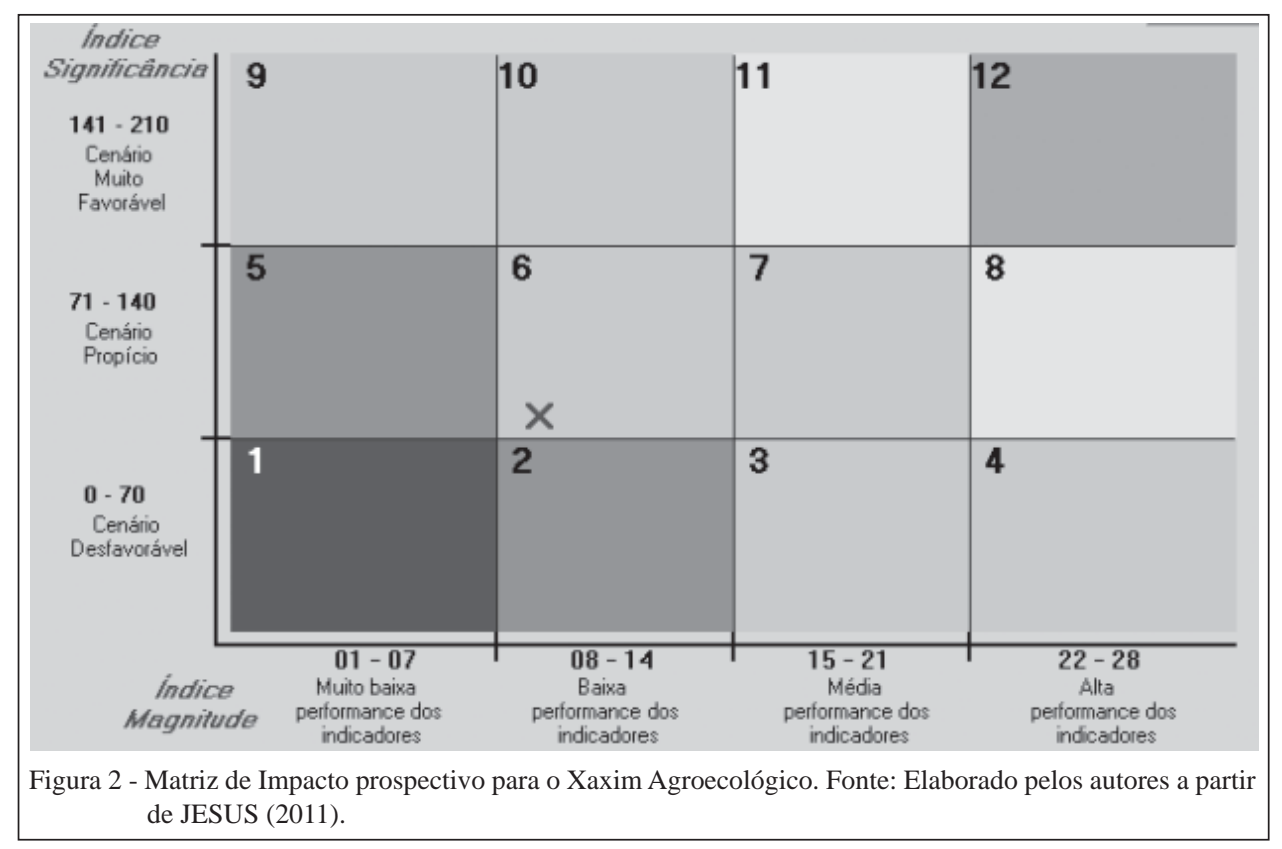

da demanda por recursos naturais, considerando uma análise comparativa do uso e consumo da água e do solo. Em termos de dimensão econômica seria importante considerar o potencial retorno financeiro e existência de barreiras de entrada (dificuldade para entrar no mercado) da referida tecnologia. Considerando a cadeia produtiva em que o Xaxim Agroecológico deverá ser inserido (SEBRAE, 2003), simulações com o Software INOVA-tec apontam para a melhora do índice de magnitude calculado, resultando em um cenário propício para a inovação com médio desempenho dos indicadores que exigirão o monitoramento e gerenciamento da introdução da tecnologia no mercado consumidor.

\section{CONCLUSÃO}

O Xaxim Agroecológico da Embrapa constitui uma tecnologia promissora, e pode vir a atender a demanda existente no mercado bem como ser uma possibilidade de fonte de renda alternativa para o campo.

O uso do INOVA-tec System v 2.0, mostrou potencial para a realização de estudos de Análise prospectiva de produtos agroecológicos, desde que sejam considerados indicadores adicionais. Para o Xaxim Agroecológico, o uso do INOVA-tec System $\mathrm{v}$ 2.0, demonstrou um potencial tecnológico com cenário propicio para a inovação, desde que ocorram melhorias nos indicadores que compõe as dimensões ambiental e econômica com a introdução de novos indicadores quando do lançamento da tecnologia por empresa a ser licenciada pela Embrapa.

Salienta-se aqui a importância do ganho socioambiental para a sociedade, isso porque 0 grande desafio para a agricultura sustentável passa pela emancipação da sociedade na qual os processos de conscientização coletiva e individual a favor da sustentabilidade ambiental devem ser participativos e peculiares de cada contexto a ser vivido.

\section{AGRADECIMENTOS}

As autoras agradecem à Fundação de Amparo à Pesquisa do Estado do Rio de Janeiro (FAPERJ), pelo apoio financeiro dado para o estudo da difusão da Tecnologia do Xaxim Agroecológico.

\section{REFERÊNCIAS}

BRASIL. Ministério do Meio Ambiente. Conselho Nacional de Meio Ambiente (CONAMA). Resolução 278, de 24 de maio de 2001, DF, 2001. Disponível em <http://www.mma.gov.br/port/ conama/res/res01/res27801.html>. Acesso em: 16 de set. 2013.

GEHLEN,I. Políticas Publicas e Desenvolvimento Social Rural. São Paulo em Perspectiva, São Paulo, v.18, n.2, p.95103, 2004. Disponível em <http://dx.doi.org/10.1590/S010288392004000200010>. Acesso em: 07 ago. 2013. Doi: 10.1590/ S0102-88392004000200010.

JESUS, K.R.E. Sistema de avaliação de impactos de inovações tecnológicas: INOVA-tec system v. 2.0. Jaguariúna, SP: Embrapa Meio Ambiente, Boletim de Pesquisa, v.86, p.1-34, 2011.

Ciência Rural, v.43, n.11, nov, 2013. 
JESUS-HITZSCHKY, K. R. E. Impact assessment system for technological innovation: Inova-tec System. Journal of Technology Management \& Innovation, Santiago, v. 2, p. 67-82, 2007. Disponível em <http://www.jotmi.org/index.php/GT/article/ view/art46/403>. Acesso em: 07 ago. 2013.

JESUS-HITZSCHKY, K. R. E.; et al. A Proposed risk assessment method for genetically modified plants. Applied Biosafety, Mundelein, v. 11, n. 3, p. 127-137, 2006. Disponível em <http:// www.absa.org/abj/abj/061103dejesus.pdf>. Acesso em: 07 ago. 2013.

LEAL, M. A. A. Suportes Agroecológicos para Plantas e Processos de sua Produção. 2009, Brasil. Patente: Privilégio de Inovação. Número do registro: PI09032444, data de depósito: 07/08/2009.

ROCHA, F.E.C, et al. Avaliação da Transferência da Tecnologia com ênfase no Feedback de clientes/usuários: método ATT e C.
Planaltina, DF: Embrapa Cerrados. Documento, v.296, p.1-53, 2010.

RODRIGUES, G. S. Avaliação de impactos ambientais em projetos de pesquisas: fundamentos, princípios e introdução à metodologia. Jaguariúna: Embrapa Meio Ambiente, Documento, v.14, p.1-66, 1998.

RODRIGUES, G. S et al. An environmental impact assessment system for agricultural R\&D. Environmental Impact Assessment Review, New York, 23: 219-244, 2003a. Disponível em <http:// www.scielo.cl/pdf/jotmi/v5n4/art04.pdf>.

RODRIGUES, G. S et al. Avaliação de impacto ambiental da inovação tecnológica agropecuária: Ambitec-Agro. Jaguariúna: Embrapa Meio Ambiente, Documento, v.34, p.1-93, 2003b.

SEBRAE. Diagnóstico da cadeia produtiva de flores e plantas ornamentais no estado do Rio de Janeiro. Rio de Janeiro: Sebrae, 2003. 167p. 